\title{
BLICKDIAGNOSE-QUIZ
}

Stellen Sie uns

Ihren Fall vor.

Bei Veröffentlichung erhalten Sie 100 Euro!

cornelius.heyer@ springer.com
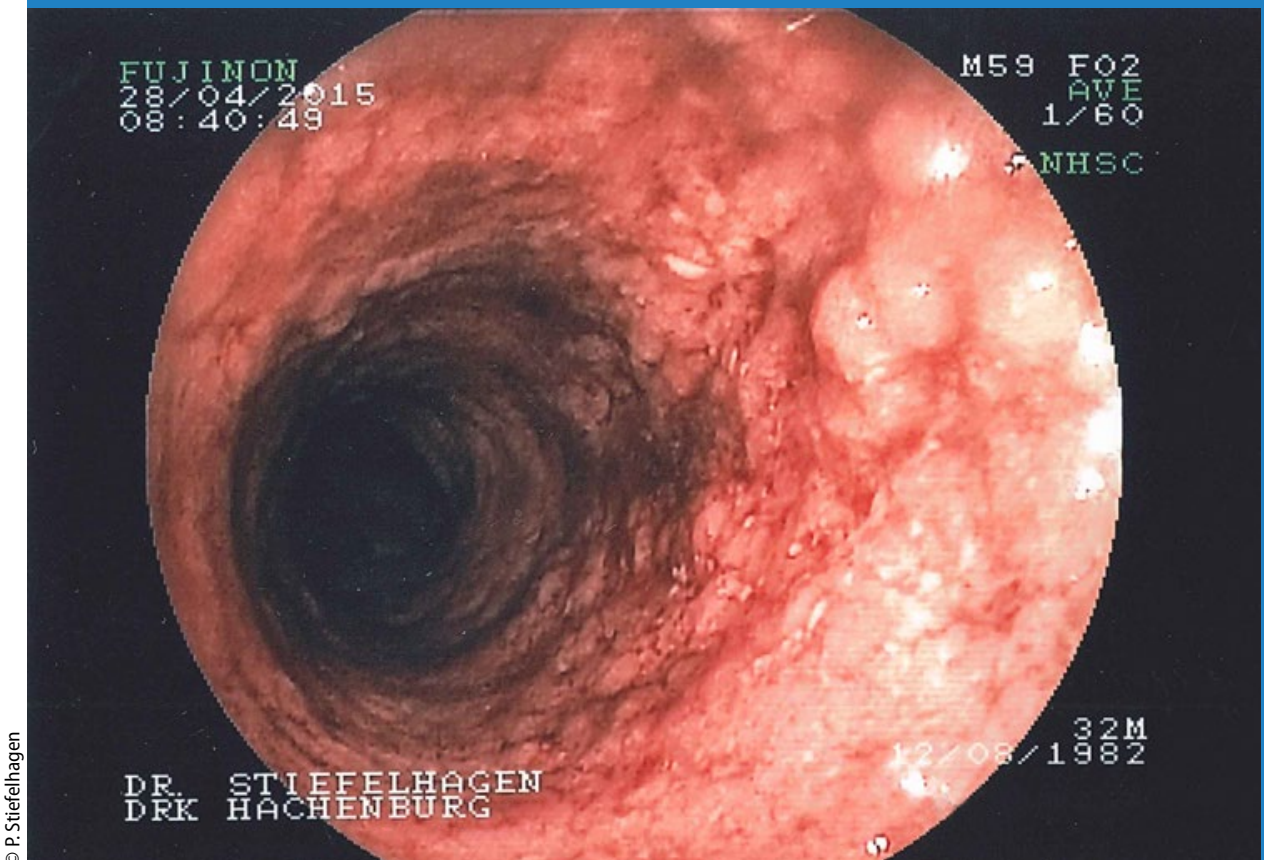

\section{Was verursacht die wässrig-blutigen Diarrhöen?}

_ Ein 28-jähriger Patient hatte sich aus beruflichen Gründen zwei Monate in einem arabischen Land aufgehalten. Etwa sechs Wochen nach der Rückkehr bemerkte er zunächst eine schmerzhafte Schwellung beider Hand- und Kniegelenke. Es wurde eine reaktive Arthritis vermutet und eine symptomatische Therapie mit einem nichtsteroidalen Antirheumatikum eingeleitet. Zwei Wochen später traten dann anhaltende, wässrig-blutige Diarrhöen auf, sodass der Verdacht auf eine infektiöse Enteritis, nämlich eine Yersinien-Infektion geäußert wurde. Doch die Untersuchung des Stuhls auf pathogene Erreger blieb negativ.
Nachdem die Diarrhöen über drei Wochen angehalten hatten und der Patient zusätzlich diffuse Bauchschmerzen angab, erfolgte zur weiteren Abklärung eine Koloskopie. Dabei fanden sich die oben dargestellten blutigen, stark entzündlichen Veränderungen.

Wie lautet Ihre Diagnose?
A) Salmonelleninfektion
B) Pseudomembranöse Kolitis
C) Colitis ulcerosa
D) Ischämische Kolitis

Auflösung auf Seite 74.

\section{Weitere Fälle finden Sie online!}

Hier können Sie in unserer umfangreichen Sammlung stöbern und Ihren diagnostischen Riecher testen.

$\rightarrow$ www.springermedizin.de/blickdiagnose $\rightarrow$ Dr. med. Peter Stiefelhagen

DRK-Krankenhaus, Alte Frankfurter Str. 12, D-57627 Hachenburg 